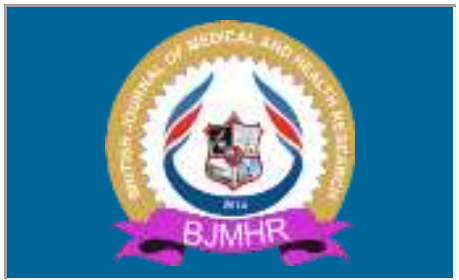

\title{
BJMHR
}

British Journal of Medical and Health Research Journal home page: www.bjmhr.com

\section{Preliminary Molecular Docking Simulation Study of Some Anti- Viral Drugs In Search Of Anti-nCOVID19 Agents}

\author{
Deepali Maruti Jagdale ${ }^{1 *}$, Heena Jalaluddin Parkar ${ }^{1}$, Aditya Suhas Gurav, \\ Pandurang Vishnu Shinde ${ }^{1}$ \\ 1.Department of Pharmaceutical Chemistry, Bharati Vidyapeeth's College of Pharmacy, \\ Sector 8, C.B.D Belapur, Navi Mumbai, Maharashtra, India 400614.
}

\begin{abstract}
Viral infection caused by corona virus named 2019-nCov has become pandemic affecting over 200 countries and leading to over 0.25 million deaths worldwide. At present there is no approved drug available specific against 2019-nCov. The present research work is focused on preliminary molecular docking evaluation of forty already available anti-viral drugs using 2GTB and 2GX4 $\mathrm{M}^{\text {pro }}$ proteins complexes. The docking simulation study result indicates that Ponatinib with highest docking score might be useful against 2019-nCov whereas, Delavirdine, Idoxuridine, Raltegravir with good docking score may be considered to treat 2019-nCov. The present article may be used by researchers to further detailed evaluation of these drugs as well as by medical professionals to fight against this infection.
\end{abstract}

Keywords: 2019-nCov, anti-viral drug, docking, coronavirus 


\section{INTRODUCTION}

Cluster of patients with pneumonia were reported in China in December 2019. ${ }^{1,2}$ Cause of the disease was identified to be a new coronavirus (2019-nCov) named due to its crown like structure. In China, more than 82800 infection cases and 4633 deaths were reported while 78792 were recovered by $5^{\text {th }}$ May $2020 .{ }^{3}$ Within a short time, coronavirus infection has become pandemic affecting over 200 countries in the world. In India, the infectious cases reported are 46476, deaths reported are 1571 while 12849 could recover by $5^{\text {th }}$ May $2020 .^{3}$ The infection develops mild symptoms such as cold, fever, coughing in approximately $80-85 \%$ of patients. $10-15 \%$ patients develop severe symptoms such as difficulty in breathing due to lung infection, headache due to mild brain hemorrhage whereas; approximately 5\% patients develop fatal symptoms leading to death. ${ }^{4}$ This virus is transmitted from one person to other person via water droplets present in air. At present there is no confirmed medicine available to kill this virus as well as, there is no vaccine available in market to prevent this viral infection. Hence, research on development of the medicines to get cure from this viral infection is become utmost important to save mankind.

Coronaviruses are positive-sense, single-stranded RNA viruses that have unique replication strategy. Coronavirus can infect respiratory, gastrointestinal, hepatic and central nervous system of human, livestock, birds, bats and many other wild animals. ${ }^{5-7}$ Coronavirus virions are spherical with diameters of approximately $125 \mathrm{~nm}$. The most prominent feature of coronavirus is spike projections emanating from surface of the virion. Within envelope of the virion is nucleocapsid. The M protein is the most abundant structural protein in the virion. It is a small ( 25-30kDa) protein with 3 transmembrane domains and gives the virion its shape. The E protein $(\sim 8-12 \mathrm{kDa})$ is found in small quantities within the virion. The E protein facilitates assembly and release of virus in the host cell. The $\mathrm{N}$ protein constitutes the only protein present in the nucleocapsid. The hemagglutinin esterase (HE) is present in a subset of $\beta$-coronavirus. ${ }^{8}$ Life cycle of coronavirus includes following major steps.

Attachment and Entry - initial attachment of the virion to host cell is initiated by interaction of $\mathrm{S}$ protein (spike) with the host cell's receptor. The S protein interaction is primary determinant for a coronavirus to infect the host species.

Replicase protein expression - next step in the coronavirus lifecycle is translation of replicase gene from the virion genomic RNA.

Replication and Transcription - viral RNA synthesis follows translation and assembly of viral replicase complexes. Viral RNA synthesis produces both genomic and sub-genomic RNAs. Sub-genomic RNA serves as mRNAs for structural and accessory genes which resides downstream of replicase polyproteins. 
Assembly and Release - following replication and sub-genomic RNA synthesis, the viral structural proteins S, E and M are translated and inserted into endoplasmic reticulum(ER). ${ }^{8}$

Based on this mode of action, the main protease $\left(\mathrm{M}^{\text {pro }}\right)$ or chymotrypsin-like protease $\left(3 \mathrm{CL}^{\text {pro }}\right)$ is suggested to be potential drug target to combat 2019-nCov. It has been reported that $\mathrm{M}^{\text {pro }}$ of 2019-nCov shares $96 \%$ of sequence alignment similarity with that of $\mathrm{M}^{\text {pro }}$ of virus causing SARS (severe acute respiratory syndrome). ${ }^{9}$

Considering these reported research outcomes the present work aims towards finding potential drug inhibitors for the protein, 2019-nCov $\mathbf{M}^{\text {pro }}$. Docking is a molecular modeling technique that is used to predict how a protein interacts with small molecules (ligands/drugs). Hence, the present article briefs on preliminary docking simulation study of 40 anti-viral drugs using SARS M ${ }^{\text {pro }}$ (PDB ID 2GTB, 2GX4) as template.

\section{MATERIALS AND METHOD}

\section{Target protein selection}

Two $\mathrm{M}^{\text {pro }}$ complexes were downloaded from protein data bank (PDB ID 2GX4 \& 2GTB) which served as templates to build 2019-nCov M ${ }^{\text {pro }}$ models. ${ }^{10}$

\section{Approved molecules}

In this study forty commercially available anti-viral drugs (Abacavir, Acyclovir, Amantadine, Amprenavir, Cobicistat, Combivir, Delaviridine, Didanosine, Efavirenz, Emtriticitabine, Famiclovir, Fosamprenavir, Foscarnet, Ganciclovir, Idoxuridine, Indinavir, Lamivudine, Lopinavir, Loviride, Methisazone, Nelfinavir, Nevirapine, Oseltamivir, Penciclovir, Ponatinib, Raltegravir, Remelesivir, Ribavirin, Rilpivirine, Rimantadine, Ritonavir, Stavudine, Tinofovir, Trizivir, Tromantadine, Vidarabine, Viramidine, Zalitabine, Zanamivir, Zudovudine) were selected to check there inhibition activity on the selected proteins. ${ }^{11}$

\section{Ligand preparation}

Two dimensional structures of the selected anti-viral drugs were generated by using Chem Draw software and were converted to mol format. These 2D structures were then converted to mol2 format and were optimized by using docking software V-Life MDS version 4.6.1 ${ }^{12}$ by GRIP docking method on PC with Intel (R) Core (TM) i3-3210 CPU @ 3.20GHz processor with windows 7 operating system. The GRIP scoring function enables fast and precise capturing and prediction of ligand-receptor interactions in the active site of proteins. GRIP docking is available as rigid as well as flexible docking, where unique conformers of a set of ligands are taken as input. ${ }^{12}$

\section{Molecular dynamic simulation}

Based upon the research reported by Chen $\mathrm{Y}$ et al. ${ }^{9}$ two proteins related to main protease $\left(\mathrm{M}^{\mathrm{pro}}\right)$ of virus causing SARS namely $2 \mathrm{GTB}$ and $2 \mathrm{GX} 4$ were selected to study binding interaction 
with the above mentioned drugs. The X-ray crystallographic structures of the proteins (2GX4 and 2GTB) were downloaded from PDB and water molecules in the structures were removed. The proteins were optimized, saved in mol format and were used for docking simulations, by using docking software V-Life MDS version 4.6.1 ${ }^{12}$ on PC with Intel (R) Core (TM) i3-3210 CPU @ 3.20GHz processor with windows 7 operating system.

\section{RESULTS AND DISCUSSION}

40 anti-viral drugs were docked to $\mathrm{M}^{\text {pro }}$ model built by V-life MDS software using 2GTB and 2GX4 as template. The docking score result(Table 1) indicates that three anti-viral drugs namely Delavirdine, Idoxuridine, Raltegravir show good docking scores ie $-56.23,-51.83$ and -52.67 against $2 \mathrm{GTB}$ whereas $-55.43,-51.71$ and -52.94 against $2 \mathrm{GX} 4$ respectively. Rilpivirine shows docking score -50.96 against 2GTB but less docking score ie -42.50 against 2GX4. Highest docking score is exhibited by Ponatinib with values -60.41 and -61.35 against 2 GTB and $2 \mathrm{GX} 4$ respectively.

Table 1: Docking score of anti-viral drugs with 2GTB and 2GX4

\begin{tabular}{|c|c|c|c|}
\hline Sr. No. & Drugs & $\begin{array}{l}\text { Docking score } \\
\text { for } 2 \mathrm{GTB} \\
\text { model }\end{array}$ & $\begin{array}{l}\text { Docking } \\
\text { score for } \\
\text { 2GX4 model }\end{array}$ \\
\hline 1. & Abacavir & -37.29 & -37.50 \\
\hline 2. & Aciclovir & -40.61 & -40.17 \\
\hline 3. & Amantadine & -5.07 & -5.07 \\
\hline 4. & Amprenavir & -39.73 & -40.90 \\
\hline 5. & Cobicistat & -34.86 & -41.53 \\
\hline 6. & Combivir & -30.84 & -31.04 \\
\hline 7. & Delavirdine & -56.23 & -55.43 \\
\hline 8. & Didanosine & -38.06 & -42.17 \\
\hline 9. & Efavirenz & -32.15 & -31.60 \\
\hline 10. & Emtritcitabine & -33.44 & -33.77 \\
\hline 11. & Famciclovir & -39.11 & -48.43 \\
\hline 12. & Fosamprenavir & -40.25 & -42.78 \\
\hline 13. & Foscarnet & -17.87 & -17.87 \\
\hline 14. & Ganciclovir & -41.45 & -44.80 \\
\hline 15 . & Idoxuridine & -51.83 & -51.71 \\
\hline 16. & Indinavir & -47.05 & -37.96 \\
\hline 17. & Lamivudine & -33.59 & -34.31 \\
\hline 18. & Lopinavir & -49.17 & -49.22 \\
\hline 19. & Loviride & -35.21 & -36.49 \\
\hline 20. & Methisazone & -25.23 & -26.09 \\
\hline 21. & Nelfinavir & -43.01 & -40.92 \\
\hline 22. & Nevirapine & -30.86 & -30.79 \\
\hline 23. & Oseltamivir & -34.90 & -35.70 \\
\hline 24. & Penciclovir & -43.36 & -43.93 \\
\hline 25 . & Ponatinib & -60.41 & -61.35 \\
\hline 26. & Raltegravir & -52.67 & -52.94 \\
\hline 27. & Remedesivir & -40.53 & -44.09 \\
\hline 28. & Ribavirin & -39.55 & -42.47 \\
\hline
\end{tabular}




\begin{tabular}{llll}
\hline 29. & Rilpivirine & $\mathbf{- 5 0 . 9 6}$ & $\mathbf{- 4 2 . 5 0}$ \\
30. & Rimantadine & -17.17 & -16.65 \\
31. & Ritonavir & -43.42 & -42.61 \\
32. & Stavudine & -35.26 & -39.53 \\
33. & Tenofovir & -42.72 & -43.92 \\
34. & Trizivir & -30.85 & -30.87 \\
35. & Tromantadine & -36.37 & -34.00 \\
36. & Vidarabine & -32.77 & -32.93 \\
37. & Viramidine & -42.98 & -39.30 \\
38. & Zalitabine & -32.24 & -31.87 \\
39. & Zanamivir & -37.38 & -37.55 \\
40. & Zudovudine & -34.83 & -34.99 \\
\hline
\end{tabular}

\section{CONCLUSION}

2019-nCov is a potential threat to the global health. However, there is neither approved drug nor vaccine available to treat or prevent this viral infection. 2019-nCov $\mathrm{M}^{\text {pro }}$ is reported to be a potential drug target to combat the virus. As 2019-nCov $\mathrm{M}^{\text {pro }}$ is reported to share $96 \%$ sequence similarity with the corresponding one in SARS, 40 approved anti-viral drugs were preliminary docked against 2GTB and 2GX4 model. Based on the docking score it is concluded that three drugs Delavirdine, Idoxuridine and Raltegravir might be active against 2019-nCov whereas, Ponatinib might become the promising drug to treat corona viral infection. Thus, the present study may become useful for the medical professionals to treat the patients showing severe to fatal symptoms.

\section{CONFLICTS OF INTEREST}

All authors declare that there is no conflict of interest in this work.

\section{REFERENCES}

1. Zhu N, Zhang D, Wang W, Li X, Yang B, Song J, Zhao X, Huang B, Shi W, Lu R, Niu P, Zhan F, Ma X, Wang D, Xu W, Wu G, Gao G.F, Tan W. A Novel Coronavirus from patients with Pneumonia in China, 2019. The New England journal of medicine. 2020; 382: 727-733.

2. Lu Hi, Stratton C.W, Tang YW. Outbreak of Pneumonia of Unknown Etiology in Wuhan China: The Mystery and the Miracle. J Med Virol. 2020; 92(4): 401-402.

3. https://www.worldometers.info

4. http://www.webmd.com/lung/coronavirus

5. Wang LF, Shi Z, Zhang S, Field H, Daszak P, Eaton B. Review of bats and SARS. Emerg Infect Dis. 2006; 12(12): 1834-1840.

6. Ge XY, Li JL, Yang XL, et al. Isolation and characterization of a bat SARS-like coronavirus that uses the ACE2 inhibitor. Nature. 2013; 503(7477): 535-538. 
7. Chen Y, Guo D. Molecular mechanism of coronavirus RNA capping and methylation. Virol Sin. 2016; 31(1): 3-11.

8. Anthony R. Fehr and Stanley Perlman, Coronaviruses: An Overview of Their Replication and Pathogenesis. Methods Mol Biol. 2015; 1282: 1-23.

9. Chen Y, Liu Q, Guo D, Emerging Coronaviruses: Genome Structure, Replication and Pathogenesis. J Med Virol. 2020; 92(4): 418-423.

10. Waterhouse A, Bertoni M, Bienert S, StuderG, Tauriello G, Gumienny R, Heer FT, de Beer TAP, Rempfer C, Bordoli L, Lepore R, Schwede T. SWISS-MODEL: homology modelling of protein structures and complexes. Nucleic Acids Res. 2018; 46(W1): W296-W303.

11. Emily LC Tan, EngEongOoi, Chin-Yo Lin, HweeCheng Tan, AiEe Ling, Bing Lim and Lawrence W. Stanton. Inhibition of SARS Coronavirus Infection in Vitro with Clinically Approved Antiviral Drugs. Emerg Infect Dis. 2004;10(4): 581-586.

12. V-Life Molecular Design Suite 4.6, V-Life Sciences Technologies Pvt. Ltd; www.vlifesciences.com.

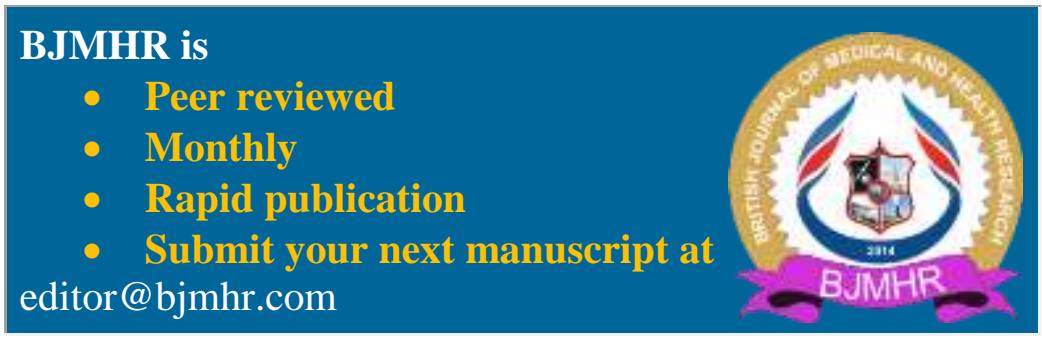

